\title{
DAWSEY, John Cowart. 2013. De que riem os boias-frias?: diários de antropologia e teatro. São Paulo: Terceiro Nome. 304p.
}

Daniel Pereira Rocha

(UFBA)
Passagens em estado de assombro, o processo ritual de John Dawsey para a construção da sua tese de livre docência evoca uma abordagem que busca no teatro elementos que possam servir como suporte para uma reflexão antropológica que dialoga diretamente com o cotidiano. O foco do trabalho gira em torno de boias-frias que vivem no interior de São Paulo na cidade de Piracicaba. Um cenário de composições ambíguas nada comum em um processo histórico de transição, favelas do mundo urbano e canaviais do mundo rural, onde o interstício que surge é nada menos que o lugar de figuras liminares: "o buraco dos capetas".

A construção etnográfica adotada faz um percurso que busca intercalar as experiências vivenciadas com paradigmas teatrais entre teorias antropológicas e sociológicas. Dawsey busca romper com os modelos estagnados de representações sociais (e teatrais). Assim, as referências que se seguem buscam uma articulação entre Victor Turner, Walter Benjamin, Clifford Geertz e Bertolt Brecht, no qual os "abalos" e "assombros", "movimentos", "ambiguidades", "dramas" e "margens" buscam traduzir aquilo que está "oculto".

As narrativas cotidianas são o guia para o teatro dos boias-frias e Anaoj, mulher preta e moradora do "buraco dos capetas", é a atriz chave para os acontecimentos que rodeiam o universo de Dawsey. É no contato com ela que o pesquisador se torna "João Branco" ou "João de Anaoj", e tem acesso a uma ampla gama de relatos que trazem em si processos de ressignificação de uma vida sofrida.

Os relatos refletem o metateatro da vida cotidana, os seus estilhaços e lampejos, na qual a vida por si só evidencia seus atores. O "espelho mágico" - categoria tomada de empréstimo de Victor Turner - evoca a capacidade que as sociedades possuem de trazer à tona experiências liminares que permitem 
enxergar-se a partir de diferentes ângulos. Ora, afinal de contas, "de que riem os boias-frias?"

As margens da vida social são, então, onde o autor busca visualizar os conflitos e elementos não resolvidos na existência cotidiana e reconhecer as arbitrariedades de associações existentes que permitem a fragmentação de qualquer "ilusão" que o "espelho mágico" possa desencadear. É o "estilhaçamento" que intensifica o significado das experiências cotidianas de uma maneira multivocal e polissêmica.

A identificação daquilo que considera "lampejos" - levando em considerações as inspirações do teatro brechtiano - faz com que reconheça a necessidade de impedir a naturalização do cotidiano para que seja possível visualizar os palcos desse teatro: o Jardim das Flores, o canavial e as carrocerias de caminhões. Aqui evoca-se a especificidade do teatro dos boias-frias ou teatro de "assombrações", com suas figuras liminares e seus dramas.

No capítulo "Tempestade chamada progresso" as expressões de raiva se apresentam como lamentações em um lugar que pode ser relacionado a um mundo, uma "nação mineira" trazendo à tona “a história de que mineiros 'caíram no buraco', na periferia de uma cidade no interior paulista, evocando um acontecimento insólito" (:114). A fuga converte-se em desânimo, o espanto vivenciado em um lugar no qual o progresso é uma "tempestade". O drama de "cair na cana" trata-se de um estado de passagem para outro - pessoas que saíram do meio rural para a cidade ressurgem como boias-frias - onde "a terra não é mais lugar de morada" e sim "terra de negócio", as dramatizações são experienciações do susto e do pasmo.

Já em "Grota dos Anjos: imagens do campo na cidade", fica claro que antes o campo era "morada da vida", no qual o trabalho refletia naquilo que servia como alimento - a comida "quente"; as novas relações estabelecidas com a terra como "negócio" da usina refletem, por sua vez, na comida "fraca". A marmita "fria" inverte a relação que só pode ser superada pela cachaça da cana, a "boia-quente"; "boia-fria precisa de boia-quente", "vai uma pinga pra nós comer". O boia-fria se apresenta assim como um "pé-de-cana".

Essas relações, então, perpassam todo o livro, "a trajetória da cana vira metáfora do percurso dos boias-frias que voltam moídos do campo; pés de cana e boias-frias viram bagaço" (:260), como também guiam a superação do desânimo para momento sofridos em momento de festa e de riso.

O boia-fria que corta cana, também por ela, pela "cana brava", ou melhor, por sua palha afiada, feito navalha é cortado. Às vezes com seu próprio podão, ele se corta. "Filho da puta não corto mais!" (...) "Espirrou sangue" (...) "Amputou o polegar" (...). Na verdade, nas relações entre boias-frias e canaviais, não se sabe quem derruba quem se são os cortadores de cana que derrubam os canaviais ou canaviais que derrubam os boias-frias. Mas essas relações também podem ser amorosas. Na palha dos canaviais se faziam "ninhos do amor" (...). Nas interrupções do trabalho (...) pessoas da turma sentavam-se nas ruas dos eitos e chupavam "mel" da cana. Também brindavam crianças, familiares, e vizinhos com "cana da roça" ao chegarem dos canaviais. (:259-260)

Esse é o cenário que propicia para a narrativa de Dawsey a abordagem do conceito de performance cuja a noção de reflexividade se constitui como elemento central para se pensar a etnografia empreendida, na qual o cotidiano de certos grupos de boias-frias traz fundamentos de um estado performático. A 
abordagem do autor se apresenta vinculada aos estudos antropológicos das formas expressivas da vida social - no qual as categorias de performance e drama social adquirem proeminência - e cujo enfoque se incorpora a eventos rituais (a partir de seu caráter liminar) no qual o teatro funcionaria como esse suporte para entendimento da realidade social. Assim, os relatos que seguem no livro acionam a noção de performance para o entendimento da constituição desse vórtice que se constitui entre espaço simbólico e representações metafóricas através de uma série de jogos e construção de papéis ligando a criatividade dos atores para um certo tipo de experiência que é lúdica e ao mesmo tempo reflexiva. Daí a necessidade encontrada por Dawsey enquanto antropólogo de percorrer o caminho entre a performance e a realidade histórica e social.

A própria escolha dos títulos lúdicos para cada capítulo evidencia essa relação de alguma forma. Em alguns como "Piscadelas de caveiras: histórias de fim do mundo"; "História noturna de Nossa Senhora do Risca-Faca"; "A Casa de Joana Dark: drama e montagem"; "Nossa Senhora e a mulher-lobisomem", trazem cenários variados e a diversidade papéis que cada ator pode assumir em determinado contexto. Nesses capítulos os interstícios e as ambiguidades são testados na realidade social entre temas que percorrem questões de gênero, raça e classe no mundo periférico: da mulher que pode ser mesmo tempo central para a manutenção de uma certa estrutura mas que ao mesmo tempo recorre às margens para a sobrevivência, ou do inverso, do homem que se nega a trabalhar como escravo para sobreviver e escolhe a dignidade e honra, ou daquele que é considerado maluco mas que detém poderes de acessar um conhecimento "sobrenatural", são nesses dilemas onde os atores acessam o subterrâneo (ou a subversão) de símbolos extraordinários ("religiosos") e trazem eles com toda força para suas vidas cotidianas.

Aquele que pode ser considerado o capítulo síntese da obra, “De que riem boias-frias?: teatro em carrocerias de caminhões", trata do trajeto percorrido pelos caminhões com os boias-frias da cidade pro canavial. Aqui é o momento em que acontece a inversão de papéis, onde é perceptível o efeito desse estado nas provocações para com as pessoas que andam pelas ruas e calçadas durante o percurso para o canavial, no qual comumente os transeuntes são chamados de "boias-frias" e "pé-de-cana", e os rapazes nas carrocerias do caminhão ressurgem como sheiks árabes, índios, cangaceiros, santos bandidos, prefeitos, etc. "Olha o sheik das Árabias!", “Diretamente da Árabia Saudita. O sheik Pagé!" (:268).

Disso não foge a relação que se estabelece entre o meio de transporte utilizado para locomoção ou dos boias-frias com as máquinas. O caminhão que transporta os boias-frias anteriormente era usado para transporte de gado, daí, se antes do êxodo rural os bois exerciam o trabalho no campo, agora são eles, os boias-frias, os seus substitutos nos campos e no caminhão. Como uma "baleia" que pode a qualquer momento se afogar no trajeto, surgem as brincadeiras das turmas: "baleia fora d'água", "ferro-velho", "tem que voltar pro ferro velho", como também o sonho de ter um carro, "meu sonho é ter um Passat. Ummm Ó, eu... uma mão no volante ou outra aqui, ó.... a menina do lado, assim, ó. Aí você vai ver" (:267). 
A "modernização conservadora" reflete também o trabalho dos boias-frias, no qual a cana era uma das matérias-primas, à época de grandes projetos como o Proálcool e Planalsucar, ou seja, eram reflexos da fé no futuro. Daí a necessidade de "calcular o lugar olhado das coisas", os risos dos boias-frias surgem das "tensões dialéticas" do cotidiano: enquanto carros são impedidos de ultrapassar o caminhão em virtude de haver um fluxo contrário intenso, entre buzinas e ronco de motores, Goiaba um dos boias-frias o desafiam "Vem, vem!", e em seguida abaixa suas calças e urina pelo caminho, toda turma se acaba de rir, ou quando, ao avistar um casarão abandonado, gritam "Olha a mansão!", “Classe A!", e desabam novamente nos risos.

Dawsey constrói uma etnografia a partir daquilo que considera "descrições tensas", "histórias de esquecimentos", o "extraordinário e espantoso cotidiano", as "margens das margens", "subterrâneos de símbolos", "montagens", "fric(c)ções", "o lugar sentido das coisas", "corpo e máscara do pesquisador". Numa articulação teórica peculiar, e em relatos etnográficos extensos identifica os limites do susto e do assombro de uma realidade ambígua no qual o riso de sujeitos explorados, os boias-frias, é sobretudo reflexão. Os escombros, as transições e as margens é o lugar em que "o riso produz conhecimento" (:.278).

Assim, o manejo singular dos dados da pesquisa de campo que culminam na diversidade de situações etnográficas abordadas pelo autor trazem uma multiplicidade de sentidos para a totalidade da obra, cuja pertinência é contextualizar o universo no qual estão inseridos e como funciona a ação performática dos atores da pesquisa na realidade social. Disso decorre ser necessário também ao leitor empreender um processo de reconstituição e inter-relação entre esses "estilhaços" e compreender não só processo empreendido por Dawsey, mas visualizar a partir dele outros caminhos a serem percorridos. Inserido em um cenário multivocal o livro "De que riem os bóias frias" oferece uma oportunidade intrínseca de acessar a teoria antropológica a partir do cotidiano e do extraordinário.

Recebido em: 27/04/2015

Aprovado em: 27/08/2015
Daniel Pereira Rocha é Mestre em Ciências Sociais pela Universidade Federal da Bahia (UFBA). 